\title{
Intravascular contrast media for imaging in breastfeeding women
}

\author{
Navneet Singh MD, Kristopher McLean MSc \\ Breastfeeding mothers may be advised to interrupt breastfeeding after \\ undergoing an imaging procedure with contrast
}

Breastfeeding mothers who require intravascular iodinated or gadoliniumbased contrast for an imaging procedure may be advised to interrupt breastfeeding and discard their breast milk for 24 to 48 hours after exposure to the contrast media. However, this recommendation, even if it is listed on product labels, is not evidence-based.'

\section{Less than $1 \%$ of the maternal dose of contrast media is excreted into breast milk}

Nearly $100 \%$ of the small amount (1\%) of iodinated and gadoliniumbased contrast media that would be excreted into breast milk is cleared from the maternal bloodstream in 24 hours. ${ }^{1,3,4}$ Although studies of clearance and excretion of contrast media in breastfeeding women are limited by small sample sizes, the results have been consistent.

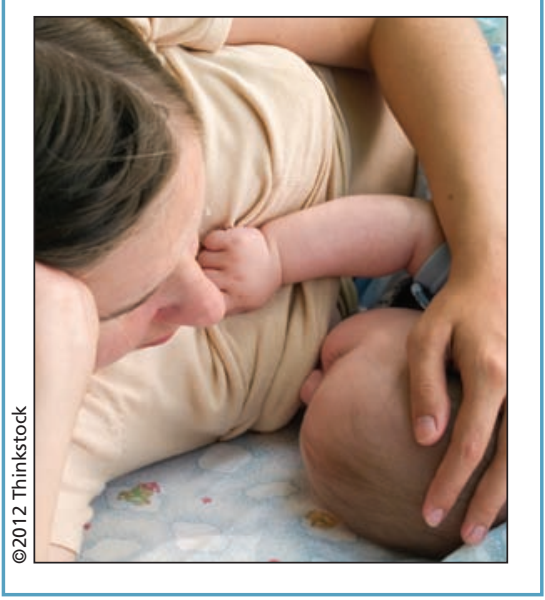

Less than $0.01 \%$ of the maternal contrast dose is absorbed from the gastrointestinal tract of the breastfed infant

The level of contrast agent absorbed by the infant $(0.01 \%$ of the maternal dose) is less than $1 \%$ of the levels of agents administered to neonates during imaging procedures. ${ }^{1,3,4}$ These studies are also limited by small sample sizes; however, the results are consistent.
Interruption of breastfeeding for $\mathbf{2 4}$ to $\mathbf{4 8}$ hours may not be a completely benign intervention

Breastfeeding has many known benefits. The interruption of breastfeeding may cause difficulties such as breast refusal upon resumption. ${ }^{2}$

Guidelines recommend that it is safe to continue breastfeeding after medical imaging with intravascular iodinated or gadolinium-based contrast

Although there are no controlled trials to directly examine the safety of breastfeeding after imaging with contrast because of ethical considerations, the evidence on excretion and absorption suggest that it is safe for mothers to continue breastfeeding. ${ }^{5}$ Interruption is a choice for the informed parent.

\section{Competing interests: None declared.}

\section{References}

1. Webb JA, Thomsen HS, Morcos SK. The use of iodinated and gadolinium contrast media during pregnancy and lactation. Eur Radiol 2005;15:1234-40.

2. Newman J. Breastfeeding and radiologic procedures. Can Fam Physician 2007;53:630-1.

3. Nielsen ST, Matheson I, Rasmussen JN, et al. Excretion of iohexol and metrizoate in human breast milk. Acta Radiol 1987;28:523-6.

4. Kubik-Huch RA, Gottstein-Aalame NM, Frenzel $\mathrm{T}$, et al. Gadopentetate dimeglumine excretion into human breast milk during lactation. Radiology 2000;216:555-8.

5. Administration of contrast media to breastfeeding mothers. In: Manual on contrast media, version 7. Reston (VA): American College of Radiology; 2010. p. 61-2. Available: www.acr.org/Secondary MainMenuCategories/quality_safety/contrast_man ual/FullManual.aspx (accessed 2012 Apr. 13).
This article has been peer reviewed.

Affiliations: From the Diagnostic Radiology Clinician Investigator Residency Program (Singh), Faculty of Medicine; and the Faculty of Medicine (McLean), University of Toronto, Toronto, Ont.

Correspondence to: Dr. Navneet Singh, navneet .singh@utoronto.ca

CMAJ 2012. DOI:10.1503/cmaj.112148

$C M A J$ invites submissions to "Five things to know about ..." Submit manuscripts online at http://mc.manuscriptcentral.com/cmaj 